\title{
Variability of arsenic bioaccessibility and metabolism in soils by human gut microbiota using different in vitro methods combined with SHIME
}

\author{
Naiyi Yin ${ }^{\text {a,b }}$, Huili Du ${ }^{\text {a,b }}$, Zhennan Zhang a,b ${ }^{\text {a }}$ Xiaolin Cai ${ }^{\text {a,b }}$, Zejiao Li ${ }^{\text {a,b }}$, Guoxin Sun ${ }^{\text {b }}$, Yanshan Cui ${ }^{\text {a,b,* }}$ \\ ${ }^{a}$ College of Resources and Environment, University of Chinese Academy of Sciences, Beijing 101408, People's Republic of China \\ ${ }^{\mathrm{b}}$ Research Center for Eco-Environmental Sciences, Chinese Academy of Sciences, Beijing 100085, People's Republic of China
}

\section{H I G H L I G H T S}

- Five in vitro gastrointestinal methods combined with SHIME (colon phase) were used.

- As bioaccessibility varied in the colon phase among these methods.

- Plenty of As(III) and methylated arsenicals by microbial transformation were observed.

- As bioaccessibility in PBET/SBRC-SHIME colon phase were closer to in vivo results for NIST 2710a.
G R A P H I C A L A B S T R A C T
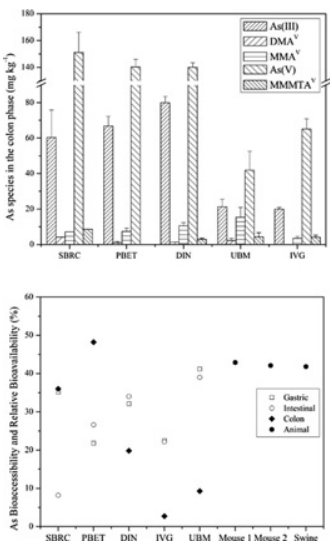

\section{A B S T R A C T}

Arsenic (As) speciation analysis is essential when evaluating the risks upon oral exposure to As-contaminated soils. In this study, we first investigated the variability in the As bioaccessibility and speciation using a combination of five common in vitro methods (SBRC, PBET, DIN, UBM and IVG) (gastric and small intestinal phases) and the SHIME model (colon phase). Our results indicate that the As bioaccessibility varies in the colon phase. An increase in the As bioaccessibility for SBRC and PBET, and a decrease for UBM and IVG were observed in the colon phase. In addition, we found different extents of methylation and large amounts of arsenite [As(III)] due to microbial reduction in the colon digests. The UBM-SHIME method displayed a higher methylation percentage of $13.5-82.1 \%$, but a lower methylation percentage of $0.2-21.8 \%$ was observed in the SBRC-SHIME method. Besides, The MMA ${ }^{\mathrm{V}}$ levels in the colon digests were positively correlated with those of As(III) and DMA ${ }^{\mathrm{V}}$, so DMA ${ }^{\mathrm{V}}$ can be considered an indicator to evaluate the As metabolic speed of in vitro cultured human gut microbiota. Based on the standard reference soil of NIST 2710a, the As bioaccessibility in the colon phase of PBET-SHIME and SBRCSHIME were the closest to the in vivo results. Combining in vitro methods and SHIME will remarkably affect the accurate assessment of potential risks to human health associated with oral exposure to soil As.

() 2016 Elsevier B.V. All rights reserved.

* Corresponding author at: College of Resources and Environment, University of Chinese Academy of Sciences, Beijing 101408, People's Republic of China.

E-mail address: cuiyanshan@ucas.ac.cn (Y. Cui). 


\section{Introduction}

Arsenic (As) is a common hazardous substance that is extensively distributed in the soil environment (Bhattacharya et al., 2007). Human exposure to soil As, particularly for children, is a major public concern and is associated with serious risks to human health because As is known as a carcinogen (Wang and Mulligan, 2008). Inadvertent oral ingestion has been considered an important exposure pathway for soil As, especially through outdoor hand-to-mouth activities by children (Ljung et al., 2006). Human health risk assessment depends mainly on in vivo bioavailability methods and in vitro bioaccessibility methods. Generally, bioaccessibility is defined as the fraction of As that is soluble in the gastrointestinal environment of human being and available for absorption, whereas bioavailability is determined as the fraction of As that is absorbed into the systemic circulation (Juhasz et al., 2009; Ruby et al., 1999). In view of the time, cost and ethical considerations associated with in vivo methods, in vitro methods are widely used in assessing human health risk. For As contaminated soils, a strong linear relationship between As relative bioavailability (RBA) and As bioaccessibility has been reported (Bradham et al., 2011; Juhasz et al., 2009, 2014; Rodriguez and Basta, 1999; Ruby et al., 1996). By establishing good in vivo-in vitro correlations, these in vitro bioaccessibility methods have been proposed as surrogates to predict the RBA for refining the risk to human health of inadvertent oral soil ingestion as an important exposure route. To date, numerous in vitro methods have been used to assess As bioaccessibility in soils (Kelly et al., 2002; Rodriguez and Basta, 1999; Ruby et al., 1996; Wragg et al., 2011). A respectable amount of information is available regarding the comparison of in vitro methods for the assessment of As bioaccessibility. Within the studies undertaken, researchers reported that As bioaccessibility varied between in vitro methods, in soils and household dust respectively (Juhasz et al., 2014; Li et al., 2014; Oomen et al., 2002). Moreover, variable As bioaccessibility has been observed with differences in the compositions of the gastric and small intestinal phases, in vitro $\mathrm{pH}$ and other parameters (e.g., soil/ solution ratio, residence time) (Juhasz et al., 2009, 2011; Smith et al., 2014).

Among those in vitro methods, the Simulator of Human Intestinal Microbial Ecosystem (SHIME) describes the colon microbial community of humans (Van de Wiele et al., 2004b) based on other in vitro methods. Van de Wiele et al. (2010) first reported the importance of the metabolism of soil As by human gut microbiota based on in vitro experiments. Other recent studies have shown that human gut microbiota actively metabolize As, and affect As bioaccessibility in food and contaminated soils (Laird et al., 2007; Sun et al., 2012). Speciation analysis is essential when evaluating risks from soil As exposure. Arsenic species that have previously been detected in the colon digests, include arsenate $[\mathrm{As}(\mathrm{V})]$, arsenite $[\mathrm{As}(\mathrm{III})]$, low-toxicity monomethylarsonic acid $\left(\mathrm{MMA}^{\mathrm{V}}\right)$ and dimethylarsinic acid $\left(\mathrm{DMA}^{\mathrm{V}}\right)$, highly toxic monomethylarsonous acid $\left(\mathrm{MMA}^{\mathrm{III}}\right)$, and monomethylmonothioarsonic acid $\left(\right.$ MMMTA $^{\mathrm{V}}$ ) of unknown toxicity (Van de Wiele et al., 2010). In addition, some studies on urine analysis by As thiolation using animal models revealed sulfur-containing methylated As metabolites, dimethylmonothioarsinic acid $\left(\mathrm{DMMTA}^{\mathrm{V}}\right)$ ), and dimethyldithioarsinic acid (DMDTA ${ }^{\mathrm{V}}$ ) (Kubachka et al., 2009; Naranmandura et al., 2007; Raml et al., 2007). As bioaccessibility in the gastric and small intestinal phases is used to estimate As potential harm to human health.
Nevertheless, As biotransformation by human gut microbiota must be considered an essential part of the risk assessment for in vitro methods for oral exposure to soil As.

This is necessary for the refinement of human health risk assessments associated with soil As exposure, when As metabolism is taken into account. Unfortunately, there are limited data of the variability in soil As metabolism by human gut microbiota regarding the combination of different in vitro methods (gastric and small intestinal phases) and SHIME (colon phase). The between-method variability can result in the indeterminacy of the As metabolism by human gut microbiota and As distribution in the colon digest and soil solid phase, and thereby of the changes in the As speciation and bioaccessibility. It was hypothesized that As metabolism by human gut microbiota in the colon phase would differ as a consequence of the variability in these in vitro methods. Therefore, in this study, five common in vitro methods (SBRC, PBET, DIN, UBM and IVG) (gastric and small intestinal phases) combined with the SHIME (colon phase) were used to (1) investigate the variability of soil As bioaccessibility in the gastric, small intestinal and colon phases; (2) determine the As speciation in the colon phase and assess differences in soil As transformation by human gut microbiota; and (3) investigate the relationship between As bioaccessibility in the colon phase and the reported in vivo results based on the reference soil (NIST 2710a).

\section{Materials and methods}

\subsection{Arsenic-contaminated soils}

In our previous study, Yin et al. (2015b) determined the transformation of As species by human gut microbiota using a combination of PBET and SHIME in five contaminated soils from mining and farmland sites in China with high As concentrations ranging from 110.9 to $802.5 \mathrm{mg} \mathrm{kg}^{-1}$. In this study, six soils including four previous soils, one Chinese reference material (GSS-5, National Institute of Metrology, China) and one reference material (NIST 2710a), were used to evaluate As bioaccessibility and speciation using a combination of different commonly used in vitro methods and SHIME. These soil samples cover a range of values for soil physicochemical properties and different concentrations of total As (Table 1). All soil samples were air-dried and sieved to a $<250 \mu \mathrm{m}$ particle size fraction for in vitro studies; this size of particle is most likely to stick to the hands of exposed humans (Kelly et al., 2002). Table 1 and Table S1 detail the physicochemical properties of the selected soils, including the concentrations of key metal elements, soil $\mathrm{pH}$, organic matter, clay, and oxalate-extractable iron (Fe), aluminum ( $\mathrm{Al}$ ) and manganese $(\mathrm{Mn})$.

\subsection{Dynamic SHIME}

The in vitro colon microbial community utilized in the experiments was cultured and maintained in a modified SHIME as previously described (Van de Wiele et al., 2004a), which consisted of five compartments simulating the stomach, small intestine, ascending colon, transverse colon and descending colon. In previous studies about SHIME, fresh fecal microorganisms were obtained from one volunteer (Laird et al., 2007; Sun et al., 2012; Van de Wiele et al., 2010), and we chose one Chinese volunteer. Briefly, fresh fecal microorganisms

Table 1

Physicochemical properties of the soils $(n=3)$.

\begin{tabular}{|c|c|c|c|c|c|c|c|}
\hline Sample & Site & Type & $\mathrm{pH}$ & $\mathrm{Fe}\left(\mathrm{g} \mathrm{kg}^{-1}\right)$ & $\operatorname{Mn}\left(\mathrm{g} \mathrm{kg}^{-1}\right)$ & $\mathrm{Al}\left(\mathrm{g} \mathrm{kg}^{-1}\right)$ & As $\left(\mathrm{mg} \mathrm{kg}^{-1}\right)$ \\
\hline Soil 1 & Chifeng, Inner Monglia & Mining & 7.4 & 21.1 & 1.5 & 23.8 & 110.9 \\
\hline Soil 2 & Dalian, Liaoning & Mining & 3.5 & 191.1 & 0.1 & 10.8 & 802.5 \\
\hline Soil 3 & Shangyu, Zhejiang & Farmland & 7.4 & 35.6 & 0.8 & 48.4 & 323.9 \\
\hline Soil 4 & Chenzhou, Hunan & Farmland & 7.6 & 27.5 & 0.5 & 53.8 & 143.3 \\
\hline Soil 5 & & GSS-5 & & 75.4 & 1.4 & 97.2 & 412.0 \\
\hline Soil 6 & & NIST 2710a & 4.0 & 34.0 & 1.7 & 10.0 & 1400.0 \\
\hline
\end{tabular}


obtained from a Chinese 28-year-old male volunteer with no history of antibiotic treatment in the six months before the study, were inoculated in the three colon compartments. Feed solution was added three times per day to provide digested nutrition for the colon microorganisms. The temperature $\left(37^{\circ} \mathrm{C}\right)$ and $\mathrm{pH}(5.6-5.9,6.15-6.4$, and 6.7-6.9 in the ascending colon, transverse colon and descending colon, respectively) (Molly et al., 1994) were controlled automatically. The SHIME reactors were continuously stirred and kept under anaerobic conditions by regularly flushing with nitrogen. After 3-4 weeks of adaptation, stable microbial communities were obtained in the respective colon compartments. The distal colon microbial fermentation activity (short chain fatty acid production and ammonium production) and community composition were investigated, and found to be consistent with those of previous SHIME runs and the in vivo situation (Molly et al., 1994; Yin et al., 2015b). For the dynamic SHIME, the feed solution contained (in grams/liter) arabinogalactan (1.0), pectin (2.0), xylan (1.0), starch (4.0), glucose (0.4), yeast extract (3.0), peptone (3.0), mucin (1.0), and cystein (0.5). After autoclaving and cooling down, the feed was adjusted at $\mathrm{pH} 2.0 \pm 0.1$. The pancreatic juice contained (in grams/liter) $\mathrm{NaHCO}_{3}$ (12.5), bile salts (6.0), and pancreatin (0.9). Autoclave distilled water and then when it cooled down, put everything inside to prepare pancreatic juice.

\subsection{Estimation of bioaccessibile As}

A variety of commonly used in vitro methods were selected to assess the As bioaccessibility in contaminated soils. In this study, we compared the soil As bioaccessibility investigated in the gastric, small intestinal and colon phases by five in vitro methods combined with SHIME. The in vitro methods evaluated were the Solubility Bioaccessibility Research Consortium (SBRC) assay (Kelly et al., 2002), the physiologically based extraction test (PBET) (Ruby et al., 1996), the German standard bioaccessibility methodology (DIN) (Deutsches Institut fur Normung e.V, 2000), the Unified Bioaccessibility Research Group of Europe (BARGE) method (UBM) (Wragg et al., 2011), and the in vitro gastrointestinal extraction method (IVG) (Rodriguez and Basta, 1999), with details provided in Table S2. In brief, soils were added to polypropylene conical centrifuge tubes with the gastric and small intestinal digests at specific soil/solution (s/s) ratios. Following the small intestinal phase, these digests were transferred into $100 \mathrm{~mL}$ anaerobic serum bottles and corresponding volumes of colon solution from the colon compartment of the dynamic SHIME system were added with double ratios ( $\mathrm{s} / \mathrm{s}$ ) of the small intestinal phase (Van de Wiele et al., 2010; Yin et al., 2015b). The bottles were capped with butyl rubber stoppers and immediately flushed with nitrogen gas for 20-30 min to obtain anaerobic conditions. The digests were shaken at $150 \mathrm{rpm}$ and incubated at $37^{\circ} \mathrm{C}$ for $48 \mathrm{~h}$ (Sun et al., 2012; Yin et al., 2015b). The experiments were conducted in triplicate. For the assessment of the As bioaccessibility, the digests of the gastric, small intestinal and colon phases were filtered $(0.45 \mu \mathrm{m})$ and analyzed by inductively coupled plasma optical emission spectroscopy (ICP-OES, Optima-2000, Perkin-Elmer Co. Ltd., USA) or inductively coupled plasma mass spectrometry (ICP-MS, 7500a; Agilent, Palo Alto, CA, USA). During ICP-MS measurement of As concentration in sample supernatants, As recovery ( $n=18$ ) was $93.6-109.2 \%$ (mean value $103.5 \%$ ) with a standard solution of $20 \mu \mathrm{g} \mathrm{L}^{-1}$.

The in vitro As bioaccessibility was calculated as follows:

As bioaccessibility $(\%)=($ invitro As $/$ total As $) \times 100$

where in vitro As = concentration of bioaccessible As in the gastric, small intestinal and colon phase, and total As = total As concentration in contaminated soils. The experiments were conducted in triplicate. One-way ANOVA was performed to determine significant differences in the As bioaccessibility for each soil using SPSS 18.0.0 (IBM).

\subsection{Arsenic speciation analysis}

All samples taken from the colon phase were centrifuged at 10 , $000 \times g$ for $10 \mathrm{~min}$. The supernatants were filtered $(0.45 \mu \mathrm{m})$ and stored at $-80^{\circ} \mathrm{C}$ until analysis. Arsenic speciation was determined by highperformance liquid chromatography coupled with ICP-MS as described. Chromatographic columns were obtained from Hamilton and consisted of a pre-column ( $11.2 \mathrm{~mm}, 12-20 \mu \mathrm{m})$ and a PRP-X100 10- $\mu \mathrm{m}$ anion-exchange column $(250 \mathrm{~mm} \times 4.1 \mathrm{~mm})$. The mobile phase consisted of $10 \mathrm{mM}\left(\mathrm{NH}_{4}\right)_{2} \mathrm{HPO}_{4}$ and $10 \mathrm{mM} \mathrm{NH}_{4} \mathrm{NO}_{3}$, adjusted to $\mathrm{pH} 6.2$ using nitric acid or ammonia. The flow rate was $1 \mathrm{~mL} \mathrm{~min}^{-1}$. As species in the colon digests were identified by comparing their retention times with those of standards [As(III), As(V), DMA V ${ }^{2} M^{2} A^{\mathrm{V}}$ and MMMTA $\left.{ }^{\mathrm{V}}\right]$ as quantified by external calibration curves with peak areas. MMMTA $^{\mathrm{V}}$ was synthesized using a mixture of MMA $\mathrm{M}^{\mathrm{V}}$ and $\mathrm{H}_{2} \mathrm{~S}$ solutions by this method (Alava et al., 2012; Rubin et al., 2014). $100 \mathrm{~mL}$ of saturated $\mathrm{H}_{2} \mathrm{~S}$ solution was added to $900 \mathrm{~mL}$ of a $40 \mathrm{mg} \mathrm{As} \mathrm{mL}^{-1}$ $\mathrm{MMA}^{\mathrm{V}}$ solution in a glass vial. The mixture was shaken overnight on a mechanical shaker. The sum of all As species in the filtrates $(0.45 \mu \mathrm{m})$ observed chromatographically was considered the bioaccessible As. The chromatographic recovery by this method has been validated (Zhu et al., 2008). Hereon, the chromatographic recovery was calculated using the total As concentration in the colon digest measured by ICP-MS divided by the sum of the concentrations of chromatographically detected As species. The recoveries were satisfactorily high: $102.2 \pm 6.9 \%$ (mean $\pm S D$ ) on average (Table S3).

\section{Results and discussion}

\subsection{Arsenic bioaccessibility in the gastric and small intestinal phases}

Fig. 1 shows comparisons of the As bioaccessibility values (0.9$41.2 \%)$ for six soils determined for the gastric $(G)$ and small intestinal (I) phases using the SBRC, PBET, DIN, UBM, and IVG in vitro methods. Synchronously, As bioaccessibility data illustrate the considerable variability between in vitro methodologies for all studied soils. For four of the six soils evaluated, the SBRC-G or UBM-G methods gave dramatically higher assessments of the As bioaccessibility than those acquired from other in vitro methods. The disparity in the As bioaccessibility may be in part reflective of the differences in parameters (i.e., gastric $\mathrm{pH}$, and constituents) for the in vitro methods. The lower $\mathrm{pH}$ in the gastric phase with higher As bioaccessibility leads to an increase in the dissolution of As and Fe (Juhasz et al., 2009; Ruby et al., 1996). In addition, organic constituents in the gastric phase can influence the solubility of As and Fe (Smith et al., 2014). Nevertheless, soil properties (i.e., total As concentration, particle size, and mineral phases) may also affect the As bioaccessibility, as reported in previous studies (Cui and Chen, 2011; Juhasz et al., 2009; Smith et al., 2014; Yang et al., 2003; Yin et al., 2015a). Presumably, the differences in As bioaccessibility are a result of synergistic effects between the in vitro parameters and soil properties.

From the gastric to small intestinal phases, the As bioaccessibility also differed. For the SBRC method, the As bioaccessibility was significantly reduced by 2.0 to 14.5 -fold in soils 1,2 , and 6 . The importance of soil Fe in controlling the As dissolution and bioaccessibility has been evidenced (Mercer and Tobiason, 2008). In contrast, increases in the As bioaccessibility using PBET-I and DIN-I for all soils except soil 1 were observed, by 1.1 to 1.7 -fold and 1.1 to 2.8 -fold, respectively. Masscheleyn et al. (1991) showed that under alkaline conditions, the As solubility is determined by solubility of Fe oxides/hydroxides. With $\mathrm{pH}$ values up to 7.0 in the small intestinal phase, the dissolved Fe concentrations increased, which can result in As desorption. Besides, the As bioaccessibility was either congruent, slightly decreased or increased following the transition from the gastric to small intestinal phases in the UBM and IVG methods. 

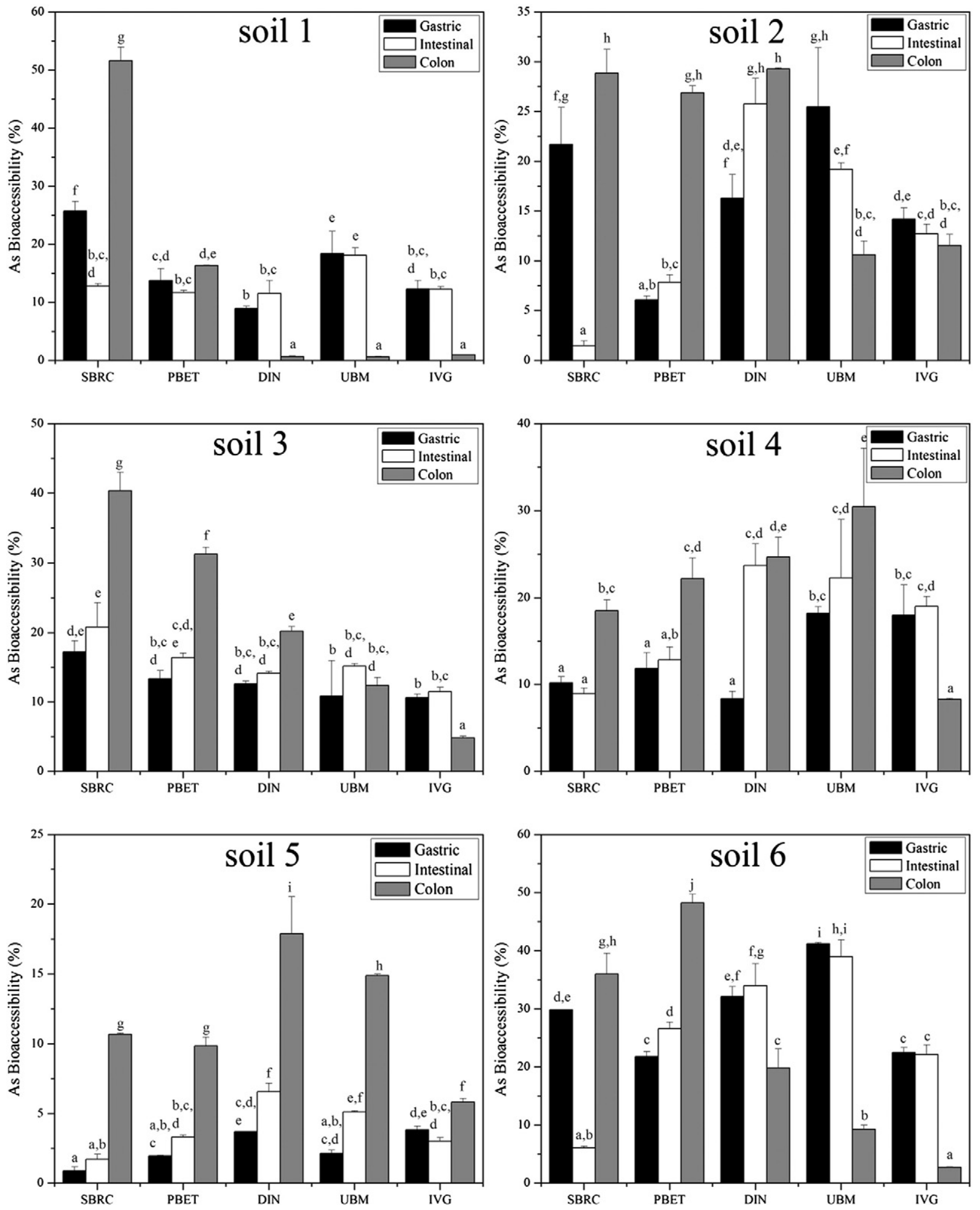

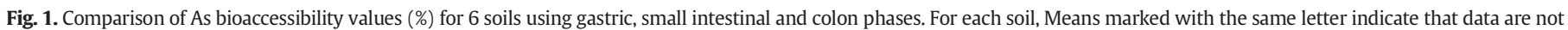
significantly different $(\mathrm{P}>0.05)$.

\subsection{Arsenic bioaccessibility in the colon phase}

In this study, we first aimed to detail the variability in the As bioaccessibility and speciation in the colon phase. For the SBRC-SHIME method, following the transition from the small intestinal (SBRC-I) to the colon phase (SBRC-SHIME-C), As bioaccessibility was 1.919.3 times than that of SBRC-I (Fig. 1). A similar increase (1.4 to 3.4-fold) in the PBET-SHIME-C As bioaccessibility was observed for all soils (Fig. 1). An increase in the As bioaccessibility in PBETSHIME-C compared to PBET-I has previously been reported (Yin et al., 2015b). In addition, the DIN-SHIME-C As bioaccessibility was greater than the DIN-I values for four of the six soils evaluated (Fig. 1). Researchers have found that As mobilization is enhanced by $\mathrm{As}(\mathrm{V})$ reduction from As-bearing minerals in the presence of As- 
reducing bacteria (Smeaton et al., 2012; Smith et al., 2014). As detailed by Tian et al. (2015) microbial Fe(III) reduction may have two opposite consequences on the fate of associated As: mobilization (Cummings et al., 1999; Islam et al., 2004) and sequestration (Coker et al., 2006; Islam et al., 2005; Jiang et al., 2013). In anaerobic environments, the adsorption ability for As is weaker due to the reductive dissolution of $\mathrm{Fe}$ (III) oxides in the presence of $\mathrm{Fe}(\mathrm{III})$-reducing bacteria; consequently, the As bioaccessibility is greatly increased. However, in the opposite case, the formation of secondary Fe-minerals during the $\mathrm{Fe}(\mathrm{III})$ reductive dissolution, can sequester As, resulting in reduced As bioaccessibility (Coker et al., 2006; Islam et al., 2005). As mentioned, As(III) oxidation and As(V) sequestration by Mn oxides can also play a small but influential role in As bioaccessibility and speciation in the colon phase (Ying et al., 2011). In this study, the As bioaccessibility was reduced by 1.1 to 12.4 -fold in five of six soils following the modification of IVG-I to IVG-SHIME-C (Fig. 1). The decrease in As bioaccessibility from the small intestinal to the colon phases has previously been reported by uniting IVG with SHIME (Van de Wiele et al., 2010). Furthermore, when the UBM method was modified to reflect the colon phase condition, the As bioaccessibility decreased in the colon phase except for some soils (i.e., soils 4 and 5).
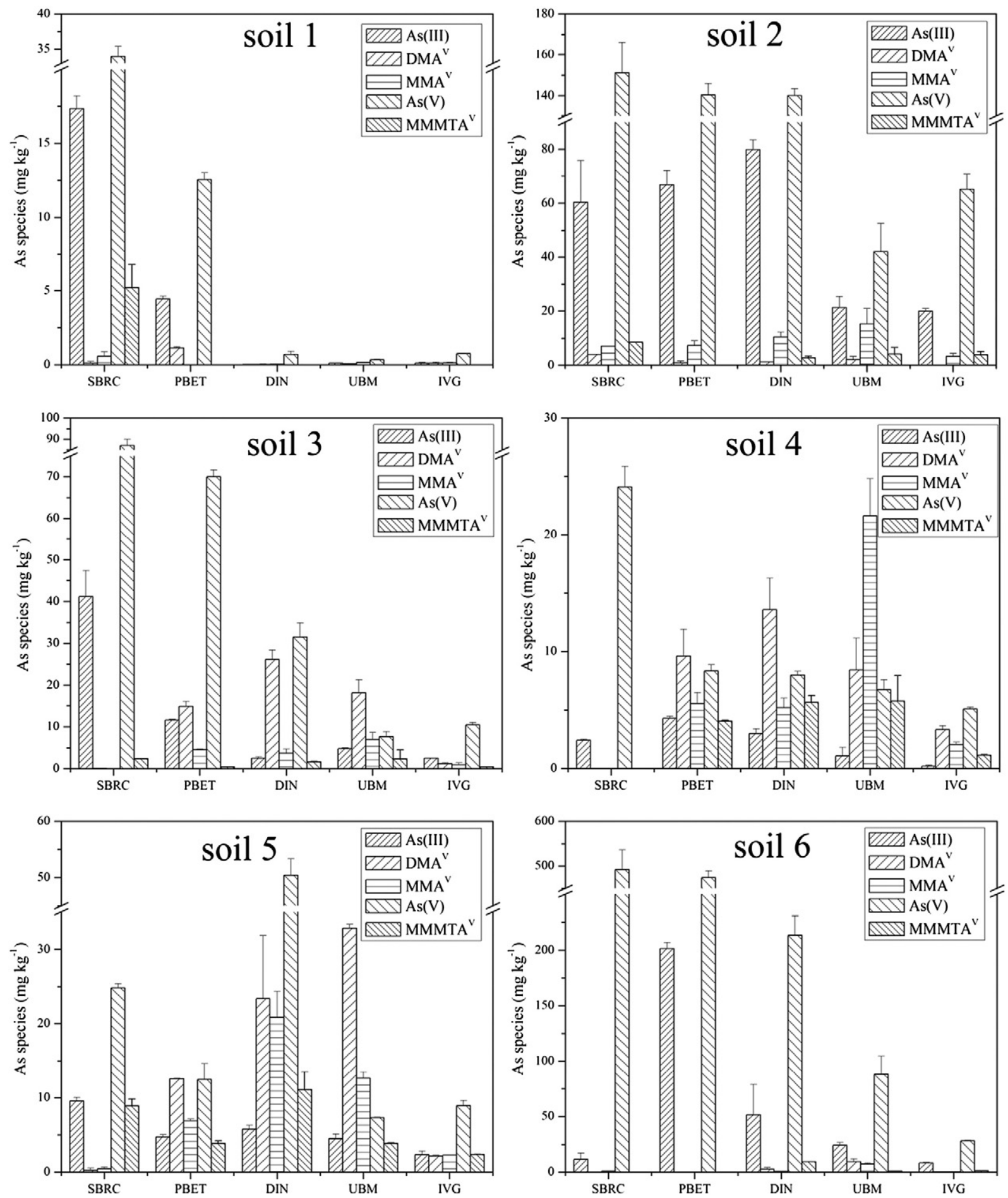

Fig. 2. Comparison of the concentrations $\left(\mathrm{mg} \mathrm{kg}^{-1}\right)$ of different species [ $\mathrm{As}(\mathrm{III}), \mathrm{DMA}^{\mathrm{V}}, \mathrm{MMA}^{\mathrm{V}}, \mathrm{As}(\mathrm{V})$, and $\left.\mathrm{MMMTA}^{\mathrm{V}}\right]$ for 6 soils in the colon phase. 


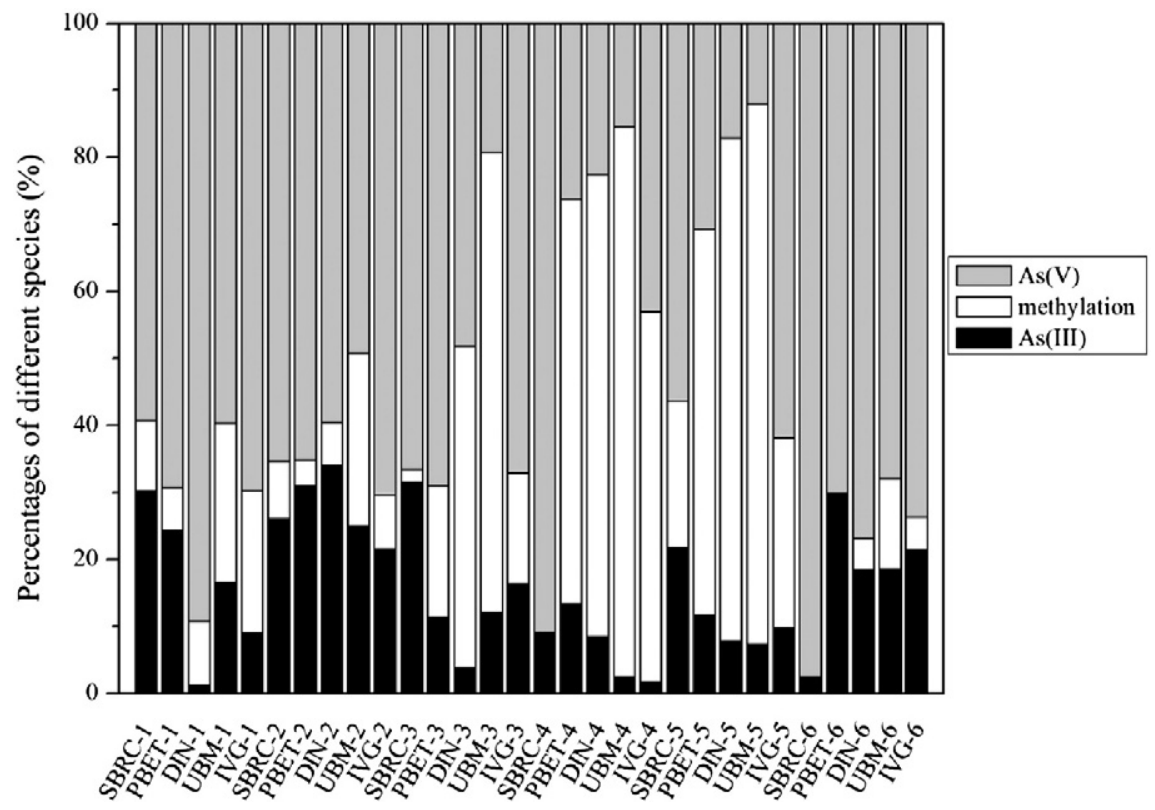

Fig. 3. Percentages (\%) of $\mathrm{As}(\mathrm{III})$, methylarsenicals, and $\mathrm{As}(\mathrm{V})$ in the colon phase (total percentages are $100 \%$ ) for 6 soils.

\subsection{Arsenic speciation in the colon phase}

Generally, As bioaccessibility and RBA are used for human health risk assessments, but it cannot be ignored that there are different As species with varying toxicities, considering As metabolism by human gut microbiota. Accordingly, compared to As bioaccessibility in the gastric and small intestinal phases, As speciation analysis can result in more accurate risk assessment to human health associated with soil As exposures. As detailed in Fig. 2, As speciation varies considerably with regard to the impacts of different constituents between methods.

UBM-SHIME-C displayed the highest methylation percentage of 13.5-82.1\% (mean value $49.1 \%$ ) for all soils. However, the methylation percentage in SBRC-SHIME-C was lower by comparison, $0.2-21.8 \%$. No As methylated species were detected in a few cases (Fig. 2). A similar between-method variability in determining the As methylation percentage for any of the six soils (Fig. 3) showed adequately different methylation abilities among these methods. Arsenic methylation and thiolation by human gut microbiota have been found previously in SHIME experiments (Rubin et al., 2014; Van de Wiele et al., 2010). Studies have indicated that $\mathrm{MMA}^{\mathrm{V}}$ can be regarded as an intermediate in the production of MMMTA $\mathrm{M}^{\mathrm{V}}$ by microbial thiolation whose main sulfide source can be $\mathrm{H}_{2} \mathrm{~S}$ by sulfate-reducing bacteria (SRB) (Rubin et al., 2014). The disparity in As methylation can be attributed to the impacts of different organic constituents for these methods. The organic constituents can be regarded as nutritional supplements to significantly increase the microbial activity (Laird et al., 2009). Huang et al. (2012) demonstrated that organic matter addition (i.e., clover or dried distillers grain) increases As methylation and volatilization from paddy soils. In our study, the presence of more or fewer organic constituents for the UBM and SBRC methods resulted in corresponding As methylation percentages for the colon digests. Moreover, for soil 1, the As bioaccessibility and methylation for all in vitro methods were generally lower. Presumably, there were higher amounts of crystalline Fe oxides and residual phase by soil As sequential extraction, which can restrict As mobility (Yin et al., 2015b).

In our study, large amounts of As(III) were observed in the colon digests due to the microbial reduction of $\mathrm{As}(\mathrm{V})$. The $\mathrm{As}(\mathrm{III})$ percentage in the colon phase varied, being $2.3-31.5 \%$ (mean value $20.2 \%$, SBRCSHIME), $11.4-31.0 \%$ (20.3\%, PBET-SHIME), 1.3-34.0\% (12.3\%, DINSHIME), 2.5-25.0\% (12.7\%, UBM-SHIME), and 1.7-21.5\% (13.3\%, IVGSHIME). Interestingly, by the Spearman correlation analysis of the data for all in vitro methods (Table 2), we found that the MMA ${ }^{\mathrm{V}}$ levels in the colon digests were positively correlated with those of As(III) $\left(r^{2}=0.42, \mathrm{P}<0.05\right)$ and $\mathrm{DMA}^{\mathrm{V}}\left(r^{2}=0.60, \mathrm{P}<0.01\right)$, whereas the correlation between the levels of $\mathrm{As}(\mathrm{III})$ and $\mathrm{DMA}^{\mathrm{V}}$ was much lower $\left(r^{2}=0.01, \mathrm{P}>0.05\right)$. Additionally, in the colon phase, the As(III) percentages negatively correlated with those of methylarsenicals $\left(r^{2}=-0.53, \mathrm{P}<0.01\right)$. This seems to indicate the interconversion among $\mathrm{As}(\mathrm{III}), \mathrm{MMA}^{\mathrm{V}}$, and $\mathrm{DMA}^{\mathrm{V}}$. During the As methylation process, $\mathrm{As}(\mathrm{III})$ may be primarily converted into $\mathrm{MMA}^{\mathrm{V}}$, and then the MMA ${ }^{\mathrm{V}}$

Table 2

Correlation matrix between the concentrations of different species, bioaccessible As concentrations, and percentages of As(III) and methylation ( $n=30)$.

\begin{tabular}{|c|c|c|c|c|c|c|c|c|}
\hline & As(III) & $\mathrm{DMA}^{\mathrm{V}}$ & $\mathrm{MMA}^{\mathrm{V}}$ & $\mathrm{As}(\mathrm{V})$ & Bioaccessible As & As(III) (\%) & Methylarsenicals & Methylation (\%) \\
\hline As(III) & 1.000 & 0.013 & $0.415^{*}$ & $0.919^{* *}$ & $0.906^{* *}$ & $0.775^{* *}$ & 0.112 & $-0.544^{* *}$ \\
\hline $\mathrm{DMA}^{\mathrm{V}}$ & & 1.000 & $0.599^{* *}$ & 0.096 & 0.222 & $-0.405^{*}$ & $0.874^{* *}$ & $0.669^{* *}$ \\
\hline $\mathrm{MMA}^{\mathrm{V}}$ & & & 1.000 & 0.337 & $0.468^{*}$ & 0.170 & $0.800^{* *}$ & 0.334 \\
\hline $\operatorname{As}(\mathrm{V})$ & & & & 1.000 & $0.939^{* *}$ & $0.564^{* *}$ & 0.036 & $-0.626^{* *}$ \\
\hline Bioaccessible As & & & & & 1.000 & $0.504^{* *}$ & 0.243 & $-0.443^{*}$ \\
\hline $\operatorname{As}(\mathrm{III})(\%)$ & & & & & & 1.000 & -0.119 & $-0.525^{* *}$ \\
\hline Methylarsenicals & & & & & & & 1.000 & $0.680^{* *}$ \\
\hline Methylation (\%) & & & & & & & & 1.000 \\
\hline
\end{tabular}

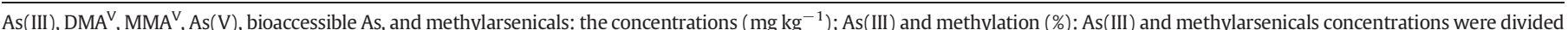
by bioaccessible As concentrations in the colon extractions.

* $\mathrm{P}<0.05$.

** $\mathrm{P}<0.01$. 


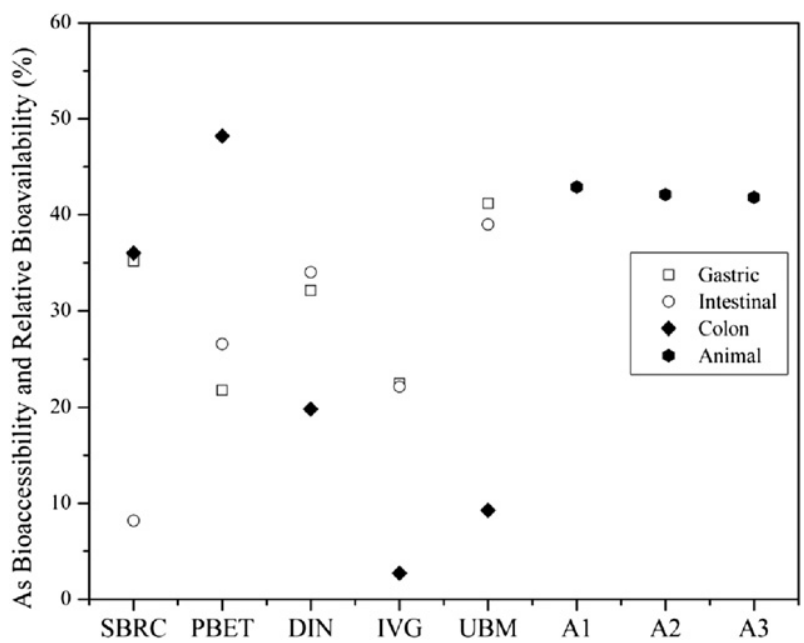

Fig. 4. As bioaccessibility (\%) using the combination of SBRC, PBET, DIN, UBM, and IVG (gastric and small intestinal phases) with SHIME (colon phase) and RBA (\%) in animal models [A1 (Bradham et al., 2011) and A2 (Juhasz et al., 2014): mouse; A3: swine (Brattin et al., 2013)] for NIST 2710a.

may be transformed into $\mathrm{DMA}^{\mathrm{V}}$. Zhu et al. (2014) summarized the As species and their biotransformation in a detailed diagram showing known enzymes for biotransformation and representative protein structures. Researchers have clearly demonstrated that gut microbiota significantly affect the As metabolism by, for example, reduction, methylation, and thiolation (Lu et al., 2013). The previous study showed that $\mathrm{As}(\mathrm{V})$ is the predominant form (nearly $>99 \%$ ) for the small intestinal digest in contaminated soils (Yin et al., 2015b). As(V) reduction and As(III) methylation should be two vital processes in As metabolism by human gut microbiota. In general, As(III) as an intermediary is converted into methylated species that eventually end up as low-toxicity $\mathrm{MMA}^{\mathrm{V}}$ and $\mathrm{DMA} \mathrm{A}^{\mathrm{V}}$ through a detoxification process. Therefore, we infer that $\mathrm{DMA}^{\mathrm{V}}$ can partly be considered to evaluate the As metabolic speed of in vitro cultured human gut microbiota, and the transformation rate can be fast with high $\mathrm{DMA}^{\mathrm{V}}$ levels. Nevertheless, the highly toxic $\mathrm{MMA}^{\mathrm{III}}$ detected as a metabolite by human colon microbiota indicates that As methylation will not lead to detoxification (Van de Wiele et al., 2010). Due to As thiolation by SBR, some thiolated arsenicals, DMMTAV with high toxicity and harmless DMDTA ${ }^{\mathrm{V}}$, are often found in the urine after inorganic As exposure (Kubachka et al., 2009; Naranmandura et al., 2007; Raml et al., 2007).

\subsection{Arsenic relative bioavailability and As bioaccessibility of NIST $2710 a$}

In previous studies, animal models (e.g., mouse, swine, and monkey) were utilized for the determination of As RBA in contaminated soils (Bradham et al., 2011; Brattin et al., 2013; Roberts et al., 2007). For NIST 2710a, these studies investigated the relationship between the As RBA determined in mouse and swine in vivo models and the As bioaccessibility by multiple in vitro methods (e.g., SBRC, PBET, DIN, UBM, and IVG). The As RBA values for NIST 2710a were $42.9 \%$ (Bradham et al., 2011), 42.1\% (Juhasz et al., 2014), and 41.8\% (Brattin et al., 2013), respectively.

From Fig. 4, we find that the As bioaccessibility values in SBRCSHIME-C, DIN-I, UBM-G, UBM-I, and PBET-SHIME-C, are relatively close $(<15 \%)$ to that of the As RBA. Comparing the results of the As bioaccessibility in the colon phase with that of the As RBA, almost all of them were lower except for the PBET-SHIME method (1.2 times the As RBA). The values are approximately 7\% (IVG-SHIME), 22\% (UBMSHIME), 47\% (DIN-SHIME) and 86\% (SBRC-SHIME) of the mean As RBA value; the results of PBET-SHIME and SBRC-SHIME are the closest to As RBA. Based on the variation in results between different in vitro (values in the colon phase) and in vivo methods, two aspects should attract considerable attention, animal experiments may not completely simulate the human digestive process, and the results in the colon phase can be considered accurate values for assessing the As risk in some soils. A comparison of different in vitro/in vivo methods and considering As metabolism by human gut microbiota can improve the accuracy of risk assessment.

\section{Conclusions}

In the colon phase, the As bioaccessibility varies and one highlighted result is that different extents of As methylation and large amounts of As(III) due to microbial reduction are observed. Additionally, we inferred forcefully that $\mathrm{DMA}^{\mathrm{V}}$ can be considered an indicator to estimate the As metabolic speed of in vitro cultured human gut microbiota. Another highlighted result is that the As bioaccessibility values in the colon phase of the PBET-SHIME and SBRC-SHIME methods are closest to the in vivo results based on the standard reference soil of NIST 2710a compared to UBM-SHIME, IVG-SHIME and DIN-SHIME. Lacking data on in vivo-in vitro (colon phase) correlations in soils, it is difficult to confirm which method can most accurately predict the As RBA. It is therefore critical to establish As in vivo-in vitro (colon phase) predictive models to evaluate the As RBA in contaminated soil.

\section{Acknowledgements}

The authors would like to acknowledge the support of the National Natural Science Foundation of China (No. 41271493). We also thank the Beijing Synchrotron Radiation Facility (BSRF) for the valuable beamtime.

\section{Appendix A. Supplementary data}

Supplementary data to this article can be found online at http://dx. doi.org/10.1016/j.scitotenv.2016.06.071.

\section{References}

Alava, P., Tack, F., Du Laing, G., Van de Wiele, T., 2012. HPLC-ICP-MS method development to monitor arsenic speciation changes by human gut microbiota. Biomed Chromatogr. 26, 524-533.

Bhattacharya, P., Welch, A.H., Stollenwerk, K.G., McLaughlin, M.J., Bundschuh, J., Panaullah, G., 2007. Arsenic in the environment: biology and chemistry. Sci. Total Environ. 379, 109-120.

Bradham, K.D., Scheckel, K.G., Nelson, C.M., Seales, P.E., Lee, G.E., Hughes, M.F., et al., 2011 Relative bioavailability and bioaccessibility and speciation of arsenic in contaminated soils. Environ. Health Perspect. 119, 1629-1634.

Brattin, W., Drexler, J., Lowney, Y., Griffin, S., Diamond, G., Woodbury, L., 2013. An in vitro method for estimation of arsenic relative bioavailability in soil. J. Toxicol. Environ. Health A 76, 458-478.

Coker, V.S., Gault, A.G., Pearce, C.I., Van der Laan, G., Telling, N.D., Charnock, J.M., et al., 2006. XAS and XMCD evidence for species-dependent partitioning of arsenic during microbial reduction of ferrihydrite to magnetite. Environ. Sci. Technol. 40, $7745-7750$.

Cui, Y.S., Chen, X.C., 2011. Lead (Pb) and arsenic (As) bioaccessibility in various soils from south China. Environ. Monit. Assess. 177, 481-492.

Cummings, D.E., Caccavo, F., Fendorf, S., Rosenzweig, R.F., 1999. Arsenic mobilization by the dissimilatory Fe(III)-reducing bacterium Shewanella alga BrY. Environ. Sci. Technol. 33, 723-729.

Deutsches Institut fur Normung e.V, 2000. Soil quality-absorption availability of organic and inorganic pollutants from contaminated soil material. Standard DIN E 19738.

Huang, H., Jia, Y., Sun, G.X., Zhu, Y.G., 2012. Arsenic speciation and volatilization from flooded paddy soils amended with different organic matters. Environ. Sci. Technol. 46, 2163-2168.

Islam, F.S., Gault, A.G., Boothman, C., Polya, D.A., Charnock, J.M., Chatterjee, D., et al., 2004 Role of metal-reducing bacteria in arsenic release from Bengal delta sediments. $\mathrm{Na}$ ture 430, 68-71.

Islam, F.S., Pederick, R.L., Gault, A.G., Adams, L.K., Polya, D.A., Charnock, J.M., et al., 2005. Interactions between the Fe(III)-reducing bacterium Geobacter sulfurreducens and arsenate, and capture of the metalloid by biogenic Fe(II). Appl. Environ. Microbiol. 71, 8642-8648.

Jiang, S., Lee, J.H., Kim, D., Kanaly, R.A., Kim, M.G., Hur, H.G., 2013. Differential arsenic mobilization from As-bearing ferrihydrite by iron-respiring Shewanella strains with different arsenic-reducing activities. Environ. Sci. Technol. 47, 8616-8623.

Juhasz, A.L., Weber, J., Smith, E., Naidu, R., Rees, M., Rofe, A., et al., 2009. Assessment of four commonly employed in vitro arsenic bioaccessibility assays for predicting in vivo 
relative arsenic bioavailability in contaminated soils. Environ. Sci. Technol. 43 , 9487-9494.

Juhasz, A.L., Weber, J., Smith, E., 2011. Influence of saliva, gastric and intestinal phases on the prediction of As relative bioavailability using the Unified Bioaccessibility Research Group of Europe Method (UBM). J. Hazard. Mater. 197, 161-168.

Juhasz, A.L., Smith, E., Nelson, C., Thomas, D.J., Bradham, K., 2014. Variability associated with As in vivo-in vitro correlations when using different bioaccessibility methodologies. Environ. Sci. Technol. 48, 11646-11653.

Kelly, M.E., Brauning, S., Schoof, R., Ruby, M.V., 2002. Assessing Oral Bioavailability of Metals in Soils. Battelle Press, Columbus, $\mathrm{OH}$

Kubachka, K.M., Kohan, M.C., Conklin, S.D., Herbin-Davis, K., Creed, J.T., Thomas, D.J., 2009. In vitro biotransformation of dimethylarsinic acid and trimethylarsine oxide by anaerobic microflora of mouse cecum analyzed by HPLC-ICP-MS and HPLC-ESI-MS. J. Anal. At. Spectrom. 24, 1062-1068.

Laird, B.D., Van de Wiele, T.R., Corriveau, M.C., Jamieson, H.E., Parsons, M.B., Verstraete, W. et al., 2007. Gastrointestinal microbes increase arsenic bioaccessibility of ingested mine tailings using the simulator of the human intestinal microbial ecosystem. Environ. Sci. Technol. 41, 5542-5547.

Laird, B.D., Yeung, J., Peak, D., Siciliano, S.D., 2009. Nutritional status and gastrointestina microbes affect arsenic bioaccessibility from soils and mine tailings in the simulator of the human intestinal microbial ecosystem. Environ. Sci. Technol. 43, 8652-8657.

Li, H.B. Li, J. Juhasz, A.L, Ma, L. 2014 Correlation of in vivo relative bioavailability to in vitro bioaccessibility for arsenic in household dust from China and its implication for human exposure assessment. Environ. Sci. Technol. 48, 13652-13659.

Ljung, K., Selinus, O., Otabbong, E., Berglund, M., 2006. Metal and arsenic distribution in soil particle sizes relevant to soil ingestion by children. Appl. Geochem. 21, 1613-1624.

Lu, K., Cable, P.H., Abo, R.P., Ru, H.Y., Graffam, M.E., Schlieper, K.A., et al., 2013. Gut microbiome perturbations induced by bacterial infection affect arsenic biotransformation. Chem. Res. Toxicol. 26, 1893-1903.

Masscheleyn, P.H., Delaune, R.D., Patrick, W.H., 1991. Effect of redox potential and pH on arsenic speciation and solubility in a contaminated soil. Environ. Sci. Technol. 25, 1414-1419.

Mercer, K.L., Tobiason, J.E., 2008. Removal of arsenic from high ionic strength solutions: effects of ionic strength, $\mathrm{pH}$, and preformed versus in situ formed HFO. Environ. Sci. Technol. 42, 3797-3802.

Molly, K., Vandewoestyne, M., Desmet, I., Verstraete, W., 1994. Validation of the simulator of the human intestinal microbial ecosystem (SHIME) reactor using microorganismassociated activities. Microb. Ecol. Health Dis. 7, 191-200.

Naranmandura, H., Suzuki, N., Iwata, K., Hirano, S., Suzuki, K.T., 2007. Arsenic metabolism and thioarsenicals in hamsters and rats. Chem. Res. Toxicol. 20, 616-624.

Oomen, A.G., Hack, A., Minekus, M., Zeijdner, E., Cornelis, C., Schoeters, G., et al., 2002. Comparison of five in vitro digestion models to study the bioaccessibility of soil contaminants. Environ. Sci. Technol. 36, 3326-3334.

Raml, R., Rumpler, A., Goessler, W., Vahter, M., Li, L., Ochi, T., et al., 2007. Thiodimethylarsinate is a common metabolite in urine samples from arsenic-exposed women in Bangladesh. Toxicol. Appl. Pharmacol. 222, 374-380.

Roberts, S.M., Munson, J.W., Lowney, Y.W., Ruby, M.V., 2007. Relative oral bioavailability of arsenic from contaminated soils measured in the cynomolgus monkey. Toxicol. Sci. 95, 281-288.

Rodriguez, R.R., Basta, N.T., 1999. An in vitro gastrointestinal method to estimate bioavailable arsenic in contaminated soils and solid media. Environ. Sci. Technol. 33 642-649.
Rubin, S.S.C.D., Alava, P., Zekker, I., Du Laing, G., Van de Wiele, T., 2014. Arsenic thiolation and the role of sulfate-reducing bacteria from the human intestinal tract. Environ. Health Perspect. 122, 817-822.

Ruby, M.V., Davis, A., Schoof, R., 1996. Estimation of lead and arsenic bioavailability using a physiologically based extraction test. Environ. Sci. Technol. 30, 422-430.

Ruby, M.V., Schoof, R., Brattin, W., Goldade, M., Post, G., Harnois, M., et al., 1999. Advances in evaluating the oral bioavailability of inorganics in soil for use in human health risk assessment. Environ. Sci. Technol. 33, 3697-3705.

Smeaton, C.M., Walshe, G.E., Smith, A.M.L., Hudson-Edwards, K.A., Dubbin, W.E., Wright, K., Beale, et al., 2012. Simultaneous release of Fe and As during the reductive dissolution of Pb-As jarosite by Shewanella putrefaciens CN32. Environ. Sci. Technol. 46, 12823-12831.

Smith, E., Scheckel, K., Miller, B.W., Weber, J., Juhasz, A.L., 2014. Influence of in vitro assay $\mathrm{pH}$ and extractant composition on As bioaccessibility in contaminated soils. Sci. Total Environ. 473, 171-177.

Sun, G.X., Van de Wiele, T., Alava, P., Tack, F., Du Laing, G., 2012. Arsenic in cooked rice: effect of chemical, enzymatic and microbial processes on bioaccessibility and speciation in the human gastrointestinal tract. Environ. Pollut. 162, 241-246.

Tian, H.X., Shi, Q.T., Jing, C.Y., 2015. Arsenic biotransformation in solid waste residue: comparison of contributions from bacteria with arsenate and iron reducing pathways. Environ. Sci. Technol. 49, 2140-2146.

Van de Wiele, T., Boon, N., Possemiers, S. Jacobs, H., Verstraete, W., 2004a. Prebiotic effects of chicory inulin in the simulator of the human intestinal microbial ecosystem. FEMS Microbiol. Ecol. 51, 143-153.

Van de Wiele, T.R., Verstraete, W., Siciliano, S.D., 2004b. Polycyclic aromatic hydrocarbon release from a soil matrix in the in vitro gastrointestinal tract. J. Environ. Qual. 33, 1343-1353.

Van de Wiele, T., Gallawa, C.M., Kubachka, K.M., Creed, J.T., Basta, N., Dayton, E.A., et al., 2010. Arsenic metabolism by human gut microbiota upon in vitro digestion of contaminated soils. Environ. Health Perspect. 118, 1004-1009.

Wang, S.L., Mulligan, C.N., 2008. Speciation and surface structure of inorganic arsenic in solid phases: a review. Environ. Int. 34, 867-879.

Wragg, J., Cave, M., Basta, N., Brandon, E., Casteel, S., Denys, S., et al., 2011. An inter-laboratory trial of the unified BARGE bioaccessibility method for arsenic, cadmium and lead in soil. Sci. Total Environ. 409, 4016-4030.

Yang, J.K., Barnett, M.O., Jardine, P.M., Brooks, S.C., 2003. Factors controlling the bioaccessibility of arsenic(V) and lead(II) in soil. Soil Sediment Contam. 12, 165-179.

Yin, N.Y., Cui, Y.S., Zhang, Z.N., Wang, Z.Z., Cai, X.L., Wang, J.J., 2015a. Bioaccessibility and dynamic dissolution of arsenic in contaminated soils from Hunan, China. J. Soils Sediments 15, 584-593.

Yin, N.Y., Zhang, Z.N., Cai, X.L., Du, H.L., Sun, G.X., Cui, Y.S., 2015b. An in vitro method to assess soil arsenic metabolism by human gut microbiota: Arsenic speciation and distribution. Environ. Sci. Technol. 49, 10675-10681.

Ying, S.C., Kocar, B.D., Griffis, S.D., Fendorf, S., 2011. Competitive microbially and Mn oxide mediated redox processes controlling arsenic speciation and partitioning. Environ. Sci. Technol. 45, 5572-5579.

Zhu, Y.G., Sun, G.X., Lei, M., Teng, M., Liu, Y.X., Chen, N.C., et al., 2008. High percentage inorganic arsenic content of mining impacted and nonimpacted Chinese rice. Environ. Sci. Technol. 42, 5008-5013.

Zhu, Y.G., Yoshinaga, M., Zhao, F.J., Rosen, B.P., 2014. Earth abides arsenic biotransformations. Annu. Rev. Earth Planet. Sci. 42, 443-467. 